\title{
Striking the balance between formality and informality in safety-critical communication: Train traffic control calls
}

\author{
Mats Andrén ${ }^{\mathrm{a}, *}$, Johan M. Sanne ${ }^{\mathrm{b}}$, Per Linell ${ }^{\mathrm{c}}$ \\ ${ }^{\text {a }}$ Centre for Languages and Literature, Lund University, Box 201, Lund, Sweden \\ ${ }^{\mathrm{b}}$ Department of Technology and Social Change, Linköping University, SE-58183 Linköping, Sweden \\ ${ }^{\mathrm{c}}$ Department of Culture and Communication, Linköping University, SE-58183 Linköping, Sweden \\ Received 16 August 2007; received in revised form 26 May 2009; accepted 31 May 2009
}

\begin{abstract}
Talk in safety-critical activities displays features that distinguish it from both ordinary conversations as well as from other institutional talk, but it also shares some features with these. Formality and informality are both interactionally accomplished phenomena, although shaped through different sources. Safety rules and pre-printed forms constitute two sources of formalization, dictating how to carry out communicative exchanges in certain types of situations, irrespective of the more specific circumstances in individual cases. Sources of informalization are the participants' need to adapt to situation-specific communicative needs, both in terms of particular situations and in terms of recurrent types of situations.

In contemporary literature, safety-critical talk tends to be treated either in terms of strict adherence to a formal code, where all informalizations are seen as potential sources of accidents, or informalization is treated as natural and inevitable, focusing on routine conditions where they are apparently harmless. In this paper, based upon detailed analysis of telephone calls between train drivers and dispatchers on the Swedish railway network, we propose a middle ground. We suggest a contingent theory of formalization, identifying four main types of informalizations, as well as discussing when and why they may be harmless and when they may be detrimental.
\end{abstract}

(C) 2009 Elsevier B.V. All rights reserved.

Keywords: Formality; Informality; Phone calls; Safety-critical communication; Train traffic control

\section{Introduction: safety-critical communication in need for conceptualization}

The requirements on talk in safety-critical environments shape it in ways that distinguish it from both ordinary conversations as well as from other institutional talk. But there are also similarities across activity types. Current research into talk in safety-critical activities tend to treat formality and informality in two equally untenable ways, with regard to our current purposes: either in terms of strict adherence to a formal code, where all deviations from this code, i.e. informalizations, are seen as potential sources of accidents, or as some ethnographically oriented studies approach these activities, treating informalizations simply as natural and inevitable, focusing on routine conditions where they are apparently harmless. Neither of these approaches is adequate for conceptualizing what, when and why informalizations may be harmless and when they may be potentially detrimental. In this article though, which is based

\footnotetext{
* Corresponding author. Tel.: +46 46 2228442; fax: +46 462223211.

E-mail addresses: mats.andren@ling.lu.se (M. Andrén), johsa@tema.liu.se (J.M. Sanne), per.linell@liu.se (P. Linell).
} 
upon 74 telephone calls between train drivers and train dispatchers ${ }^{1}$ on the Swedish railway network, we will suggest a contingent theory of formalization and informalization. We will argue that the effects of different kinds of informalizations depend both on their nature and the situational context in which they appear. Some informalizations are harmless, especially if occurring in routine and expected situations, whereas other informalizations may have dangerous consequences, especially when occurring in non-routine, improvised, and often complex, situations.

Safety-critical talk has important functions in socio-technical systems such as train traffic control, air traffic control, and subway systems (see, e.g. Sanne, 1999; Heath and Luff, 1992), which is a reason in itself for studying how they are enacted in actual practice. Partly for the same reasons, safety-critical talk is also a good site for studying the convergence and possible conflicts between formality and informality, caused by competing demands for safety, efficiency and creation of trust.

Accordingly, this paper has two main purposes. First, we aim to theorize the notions of formality and informality, as well as formalization and informalization, and to account for their import in this specific kind of institutional interaction. We suggest that formality be seen as strict norms of discourse and interaction to which participants may, or should, orient to. Informality would then be the result of (partial) suspension of these strict norms. The terms formalization and informalization will be used about the processes of modifying norms in situ, towards more of formality and informality, respectively. Our second aim in this paper is to analyze what kinds of safety consequences specific kinds of informalizations may have. This, we argue, will outline the tensions between safety, efficiency and sociability.

The paper is organized as follows. We begin by discussing institutional demands on safety-critical talk, in relation to previous research on the subject. Thereafter, we will review the relevant literature on formality in conversation analysis, highlighting some of its limitations, and define our two central concepts, formality and informality. After briefly describing our data corpus we then present two analytical sections. The first identifies types of informalizations in ordinary train traffic control calls in Sweden in contexts where they turn out to be harmless. The next section, based upon an official report, identifies informalizations in a context where they brought about a near-miss incident. Finally, we shall critically discuss the notions of formality, the practitioners' concept of conversational discipline as well as addressing questions of which forms of, and when, informalizations are potentially detrimental to safety.

\section{Striking the balance between formality and informality}

Train traffic control calls (TTC calls) are subject to various institutional demands - including, but not limited to, safety considerations. This section provides a brief look into these institutional features, from several points of view. First, we characterize TTC calls as a communicative activity type and how it has to meet a heterogeneous set of institutional demands. Second, we discuss the historical background of the institutional demands for formality in the Swedish railway, highlighting how issues of formality and informality have been much discussed within the practice itself. Finally, we broaden the view with a short discussion of research on safety-critical talk within air traffic control, with a critical eye on how the institutional demands are framed in this research.

TTC calls are carried out using ordinary mobile phones, supporting cooperative work among physically dispersed personnel. Phone calls are not the only communication channel available to train drivers as there are also computerized signaling systems, signposts and optical signals such as red and green lights. As a communicative activity type, TTC calls are of an institutional and transactional kind (Linell, in press). Their general phase structure fits that of other transactional phone calls (Hopper, 1992): there is a short opening phase (with summons, identifications, greetings, etc.), a main activity (with message delivery and receipt, i.e. stating the reason for the call, and resolving issues related to this) and a brief closing phase. The most formal parts are the opening, which is present in all of the analyzed calls, and certain parts of main activities. Examples in the empirical sections (5 and 6) will further substantiate these claims.

Within the practice, TTC calls are called "safety calls" (Swedish: säkerhetssamtal) both by practitioners and the administration. This reflects the fact that safety matters are a very important aspect of these calls. However, as we will see, the enhancement of safety is - in actual practice - not their only function. We will therefore use the more neutral term "TTC calls". Institutional demands on formal performance of these calls are legitimized precisely by a concern for safety. TTC calls take place when there is no other technology available that achieves safe traffic such as the automated train control (ATC) system.

${ }^{1}$ UK signallers, Swedish: tågklarerare. 
Many of the situations where other kinds of technology do not cover the needs are regulated by safety rules specifying that calls must take place, and that they must be carried out in certain ways. Examples of such regulated situations are confirmation of train meetings on the stations of non-automated regions, coordinating trains running in both directions on single-track lines, entries into automated sections, changes of train identification numbers, timetable modifications, temporary speed limitations, changes of routes and even destinations, etc. The underlying idea is, of course, that formal communication reduces the risk for misunderstandings and possibly dangerous actions that stem from mistaken identifications, locations, actions and so on. Formality hence consists in shared and prescribed resources for achieving structured talk with unambiguous references. The resources mainly take the form of specific terms and expressions, and obligatory communicative acts. Examples of such obligatory acts are repetitions of previous utterances in certain contexts and verbal "signing" of order exchanges. In many cases, utterances are also supposed to be delivered in more or less fixed sequential orders. Accordingly, TTC calls may be seen as a kind of "safety barrier", but below we will see that at the same time, they are themselves quite vulnerable to problems due to misunderstandings or omission of information.

Safety matters are not the only aspect of TTC calls. The calls are also used to meet another important institutional demand - achieving efficient traffic flow. ${ }^{2}$ The demands of safe traffic and efficient traffic flow both require communication between drivers, who have limited access to information about other trains and about the overall traffic situation, and train dispatchers, who have this information but lack direct access to the conditions of the single train out there (Sanne, 2001; Olsson et al., 2000). Accordingly, phone calls are also used for drivers' reports of problems and emergencies or dispatchers' passing on information on movements of other trains on the same routes.

While TTC calls thus involve prescribed forms of issuing and confirming orders, obligatory exchanges of information, etc., the communicative activities at hand also involve the need to topicalize things that are not strictly task-related. First, there is safety-related information that is not part of the formally prescribed talk. Secondly, drivers and dispatchers also deal with issues that have little to do with safety considerations, but are motivated by concerns for a smooth and efficient traffic flow (Olsson et al., 2000). ${ }^{3}$ Parties cooperate to achieve common tasks, similar to air traffic controllers and pilots (Sanne, 1999, 2003; Pomerantz and Fehr, 1997). Thirdly, we are faced with interaction where both of the participants are professionals, performing TTC calls with colleagues again and again. They may therefore wish to display and sustain mutual sociability and mutual trust. While dispatchers can influence the work of the drivers by several other means than the phone calls, the calls are the only channel at their disposal that allows for personalized and relational talk. Under certain circumstances, participants occasionally slip into "sociably motivated" talk, even gossip. In sum, TTC calls are subject to institutional demands of safety, efficiency and sociability.

TTC calls have a socio-cultural history that has shaped how they are currently conceptualized and framed. Historically, the Swedish railway organization was built up on the model of military organizations, and was in fact partly run by militaries in its mid nineteenth-century history and later by former military officers. Communication forms were partly copied from military models. A notion of "conversational discipline" was adopted, basically implying the rule "stick to formality". The inspectorate (later called The Swedish Rail Agency) has repeatedly conducted thematic investigations on safety-critical talk that one time after another has identified major problems with a deficient "conversational discipline" (Järnvägsinspektionen, 1994, 1997, 2003). It has then been claimed that TTC talks are often performed in sloppy ways, i.e. they are not kept "formal" enough. The main criticisms are, first, that the prescribed forms regulated by rules and formal procedures are not always heeded, and various forms of local jargon are sometimes being used, and secondly, that topics are sometimes brought up that are not considered transactional enough, that is, parties talk about things that they should not talk about. The latter has then been judged with reference to the tasks as they are defined by the rulebook, which is a much more narrow definition of task-relevance than what the participants themselves stick to.

Framing TTC talk in this way has also characterized investigators' causal attribution of accidents. Investigators have attributed a large number of incidents and accidents to "bad conversational discipline", at least as a contributory cause. Indeed, informalizations can sometimes be identified as a cause of misunderstandings or omissions which have clearly contributed to some accidents (Katastrofkommissionen, 1987; Järnvägsinspektionen, 2001, 2002). On closer

\footnotetext{
${ }^{2}$ There are also train traffic calls taking place between dispatchers and railroad workers and between dispatchers themselves, but these kinds of calls are out of the scope of this study.

${ }^{3}$ In focus group sessions conducted by one of the authors (Sanne), the distinction between talk motivated by safety and talk motivated by smoothness (efficiency) was repeatedly emphasised by train dispatchers and drivers.
} 
scrutiny though, even though exhibiting informal features, the number of events caused by informalizations is quite small. There is a need for developing more elaborated and nuanced concepts.

In line with the emphasis on "conversational discipline", the railway inspectorate and other practitioners have pointed to air traffic control as a desirable model of communication also for train traffic control (Halliday, 1994; Murphy, 2001). This argument requires a critical assessment, based upon empirical research in the area. Air traffic control is seen as both safe and efficient, and part of the practice is self-correction in which controllers listen to recordings of themselves, not only in case of accidents as in train traffic control. Air traffic control is, however, different from train traffic control calls in one important respect: talk is used as the main means for controllers to guide airline pilots, rather than as one of many, as in train traffic control; in the latter case, dispatchers' talk to drivers is used when there is no other technology (automated routes, signals) to guide them.

Regarding air traffic control talk, it is often assumed that strict formality is necessary. For example, it is argued that formality is required in order to ensure a shared and mutual understanding of objects, agents and action measures referenced. This is referred to as the accuracy constraint (Morrow et al., 1994). In addition, formality may function as a compensation for bad external conditions, such as low audibility, for example through involving repetitions of others' contributions when talking. Repetitions are also often used as a remedy in situations in which parties end up out of phase with each other or the prescribed sequence. Air traffic control talk is fairly formal and partly even ritualized. Participants are accustomed to holding on to certain grammatical structures and lexical resources. Explicit means are sometimes used to prevent mistakes. For example, the imposition of an instruction to "maintain Flight Level 150" prevents pilots from assuming a default procedure in a departure sequence, which would be climbing further (Sanne, 1999).

But on closer scrutiny, air traffic control is not always as completely focused on formality and lexical correctness as one might assume (Sanne, 1999). In addition to the accuracy constraint, there is also an efficiency constraint (Morrow et al., 1994). Various resources (flight strips, radar image, body language, sequential order, etc.) make communication in between controllers understandable despite that they often omit the aircraft identification or their own identity when coordinating traffic. Also, air traffic controllers engage in bartering in their communication with flight crews (Sanne, 2003). Crews are greeted and thanked. Controllers sometimes give explicit accounts in terms of safety reasons for exceptions to default procedures as a way to convince crews that their actions are legitimate, and in this way they show their proficiency and trustworthiness. They also acknowledge the crews' cooperation. Flight crews' requests for expedient shortcuts are almost always accepted, sometimes even suggested by controllers. Finally, even in air traffic control there are other demands too, and as it turns out, there is also talk that is not strictly task-included, as defined by the rule-book, but which is nonetheless seen as culturally significant and work-related by the participants. Therefore, in actual practice informalizations do occur also in air traffic control. It should be noted that accuracy is heeded over efficiency, which means that "repair work" has precedence over efficiency. The efficiency constraint though tends to produce accuracy in the first place, reducing the need for repair (Sanne, 1999).

Our analysis shows that in train traffic control talk some of these informalizations work out well. Many practitioners also endorse this argument, as opposed to the inspectorate. For us, some relevant questions will be: When and how can informalizations be functional? What types of informalizations may be detrimental to safety? How can formality and informality be balanced?

\section{Searching for a contingent theory of talk in safety-critical activities}

Research on safety-critical communication can be described broadly in terms of two quite different strands. The formal code approach moralizes over practitioners' unintended slippage between nearly identical words that have different meanings, sometimes with a potential for misunderstandings and, implicitly, accidental outcomes (e.g. Cushing, 1994; Halliday, 1994; Murphy, 2001). By contrast, ethnographically oriented studies, such as some workplace studies, tend to treat informalizations simply as natural and inevitable. This line of research is most often directed at the routine achievement of everyday collaborative activity, demonstrating how practitioners compensate for informalizations such as omissions, incorrect phrases, or misunderstandings through different kinds of repair with the help of familiarity with the situation, artifacts at hand, visual cues and the like, sometimes even in anticipation (e.g. Heath and Luff, 1992). Less is said about situations which involve serious problems, or even accidents, and the potentially different picture that would emerge when analyzing informality in such situations.

There is clearly a gap in between these two approaches to safety-critical communication and neither of them is satisfactory for our current purposes. The formal code approach is falsified by prevention and repair work analyzed in 
workplace studies (e.g. Heath and Luff, 1992; Sanne, 1999). However, accident investigations also show that such repair work is not always in place (e.g. Banverket, 2004). Hence, there is a need for a theory of middle ground that recognizes the power of repair work and the possibility for laxing the demands of formality in certain, specified situations, while also stressing the need for formality in certain critical situations. The theory should also acknowledge that both formality and informality are achieved through certain means, thus stressing their performative character, opening up for a detailed description of different kinds of formality and informality, and the ways that they interplay.

What is formality in discourse, strictly speaking? In the CA literature, there is often a very broad and vague definition: any aspects of language use and interaction deviating from the self-organizing processes in impromptu conversation are considered formal (Atkinson, 1982; Drew \& Heritage, 1992; McHoul, 1978). For example, Atkinson (1982) defines "formal" precisely as "non-conversational", and pays particular attention to turn pre-allocation in multi-party interactions, i.e. situations with an audience present. Atkinson argues that formality is (or at least can be) functional; it is designed to solve the practical problem of "achieving and sustaining the shared attentiveness of co-present parties to a single sequence of actions" (Atkinson, 1982:97). Atkinson argues that most professional-client encounters are "formal" too, mainly because of restrictions on topics. This recognition is in line with our argument about the performative character of formality. The major advantage of his concept is the recognition that "formal organizations" would not work without some features of "informal", i.e. conversational, staging of transactional tasks.

Still, Atkinson's definition of formality is clearly insufficient to analyze the features of safety-critical talk and its vulnerabilities. We deal with dyadic interactions, and turn-taking is not the primary problem for parties in train traffic control calls, compared to the situations described by Atkinson. We are more concerned with problems of turn design, the linguistic formulation of turns, and the sequencing of particular communicative contributions. ${ }^{4}$ We need concepts that acknowledge that formality does not come by itself, no matter if it is routinized or not, but to some extent it has to be achieved in every new situation - "routine as achievement" (Schegloff, 1986). There is a need for more precise and elaborated concepts to explain sources of both formalizations and informalizations in safety-critical activities. Finally, the concepts should also allow us to distinguish harmless from potentially safety-critical informalizations.

As pointed out by Irvine (1979), the terms "formality" and "informality" are used in quite different ways by different researchers, and in many cases they remain undefined. For this reason, it is important to be clear about what is meant by these terms. We propose a rather precise definition of formality, which is in line with members' understanding, namely as "conversational discipline" (acting in accord with the rule book). A certain aspect of talk is considered to be "formal" if it must, according to officially standardized and recognized institutional conventions or prescriptions, be obligatorily carried out (a) on every occasion when a specified type of situation is at hand, (b) in a predefined sequence, and (c) in a certain fixed linguistic form, irrespective of specific circumstances in individual cases; that is, even if some aspects of the talk would appear somewhat redundant in the specific individual case, the prescribed utterances have to be included. In line with this definition, informalization is viewed here as participants' adaptation of talk to local circumstances and communicative needs in specific individual situations. The definition makes the content and practical enactment of informalization an empirical question. It also makes it possible to discern goals and sources of formalization and to see informalization as the other part of the balancing act. Regarding terminology, we use the terms formalization and informalization whenever we refer to the general performative and dynamic character of formality and informality. When we refer to features of actual and observable conduct, we use the terms formalizations and informalizations.

Some conceptualizations from previous CA research are useful to describe some of the more common types of informalizations and should thus be mentioned here. First, most formal communicative activity types (except, perhaps, for "pure" ceremonies) contain some elbow-room for informalizations. Activity types with a relatively high degree of formality are the performances of telephone survey interviews (Maynard et al., 2002; Maynard and Schaeffer, 2006) and various testing situations (Marlaire and Maynard, 1990), which are supposed to be carried out in exactly the same, formal, way with each and every interviewee or testee. Nonetheless, since they occur in situated interactions, some minor variations in performance are bound to appear, for example in prosody and minor lexical detail. These have sometimes, from the standpoint of those who developed the methodologies, been regarded as insignificant modulations on an obligatory, scripted formal base. However, more importantly, professional experience and the detailed conversation-analytic studies have shown that participants in these activity types cannot avoid larger

\footnotetext{
${ }^{4}$ Irvine (1979:776) also notes this distinction between formality in the sense of certain kinds of turn-taking and formality in the sense of structured utterances.
} 
deviations from prescribed practice, due to the dynamics of conversational interaction (Stax, 2004). There are also conventionalized informal ways of carrying out formally required tasks. In sum, informalization in other activities comes in several forms. Accordingly, a number of different forms can be expected to appear in TTC calls too.

Second, theories of transactional (task- or business-related) vs. non-task-related and relational talk also conceptualize sources of informalizations. The distinctions relational vs. transactional talk and informal vs. formal talk are by no means the same; there is only a loose coupling. "Relational talk" has been much discussed in the literature on "small talk" (e.g. several articles in Coupland, 2000). Much of this discussion concerns the function of relational talk within institutional talk activities. Relational, socially motivated talk would be one kind of talk that is non-obligatory in terms of task requirement (Coupland, 2000:89). However, such talk is often more than just tangential to the task of solving taskoriented problems; it may have functions more close to the tasks. For example, McCarthy (2000) studied service encounters of two types: hair-dressers' talks with their clients (less than 10\% is transactional talk, mainly taking orders), and driving lessons (with more of transactional, especially instructional, talk), and he proposed a classification of talk with respect to the transactional vs. non-transactional distinction with four categories (p. 104):

1. Transactional talk.

2. Transactional-plus-relational talk: contains some comments and remarks that are not obligatory from a transactional point-of-view.

3. Relational talk, which, however, is often touched off by and develops out of transactional-plus-relational talk (2).

4. Phatic talk, e.g. about the weather or last night's football match.

In a study of talk between shop assistants and customers in Swedish supermarkets (information centre, delicatessen counter with manual service, checkout tills), Tykesson-Bergman (2006) documented similar mixtures of purely transactional talk with various non-transactional and relational talk. Such a tension between task-included and various other sorts of talk can be expected in train traffic control too and the analysis will elaborate further on this.

In sum, a precise definition of formality and a specification of what kinds of formality are relevant in a particular communicative activity type makes forms of informalizations an empirical question and enables us to approach the question of how these relate to safety issues. The various conceptualizations regarding sources of formalization and informalization from the literature provide a point of departure for comparisons across different kinds of activities and practices. They also provide an opportunity to approach more general questions of what shapes informalizations and formalizations, in both safety-critical and other kinds of talk.

\section{Data for comparative analysis}

This article is based upon two sources of primary data. The first consists of 70 TTC calls belonging to a larger corpus of 194 calls $^{5}$ recorded in early 2005 (Andrén, 2005), coded as TTC:1-194. They were recorded in southern Sweden and the dispatchers are all working at a remote train dispatch centre called Newbury in our English presentation of data. The drivers were on duty on regular passenger trains. In some cases there were no other personnel on the train apart from the driver. The calls were recorded under somewhat varying conditions, but none of the calls in this corpus involved serious miscommunication or outright accidents. Most of them are from routine working conditions. Data from this corpus is used in the first empirical part of this article.

The other data used in the paper are transcripts, coded as TTC:BV1-4, from the investigation of an incident where two trains could have collided. The official report (Banverket, 2004) contains rather detailed transcripts of a sequence of four TTC talks between two train dispatchers and one driver. The inclusion of both non-problematic calls, and calls in relation to problematic situations, allows contrastive analysis, which is important here given the aim here to provide a more nuanced view on the role of formalized and informalized aspects of the talk and for developing a contingent theory of when informalizations may cause accidents.

Even though the transcripts have been translated into English here, all analyses were of course performed on the Swedish original transcripts and recordings. (A description of the transcription conventions used is available in section 8 and the Swedish originals, with interlinear English translations, are available in the Appendix.)

\footnotetext{
${ }^{5}$ The calls that were excluded from this larger set of recordings are calls between dispatchers and railroad workers, which are not part of the analysis in this article.
} 


\section{Analysis of informalizations under routine working conditions}

An overwhelming majority of TTC calls do not, of course, give rise to accidents, and the ones recorded in 2005 are no exception. They were mostly of a routine character, often involving informalizations such as informalized variants of prescribed formal wordings and insertions of additional informalizations within more formal wordings in transactional communicative projects. Both of these two types of informalizations are sourced from ordinary conversation and routine.

The following TTC call concerns routine matters and it illustrates how both formal and informal aspects of talk are simultaneously present, and that both have to be achieved actively.

(1): TTC 45

1.

2. DISPATCHER: the remote in Newbury

3. DRIVER: yeah hi the driver on ninety-five zero eight

4. DISPATCHER: hi there hi

5. DRIVER: at last arrived at Oaktown

6. DISPATCHER: at last arrived in Oaktown yeah

7. DRIVER: yes

8. DISPATCHER: uh tu- uh tu- uh Svensson's thanking so much

$9 . \quad$ here then yeah

10. DRIVER: Carlsson here yeah

11. DISPATCHER: Carlsson yeah

$12 . \quad(0.5)$

13. DRIVER: yeah

14. DISPATCHER: thanks bye

$15 . \quad(0.5)$

16. DRIVER: thanks bye

17. DISPATCHER: bye

18. ((click))

Let us have a closer look at some of the formal and informal features of this call. It starts with the phone ringing (cf. Schegloff, 1968), and the dispatcher answers the phone by identifying himself (line 2). He uses the prescribed form of identification for dispatchers. Since there are several line control centres in Sweden it is important to mention the name of the specific centre being called in order to avoid possible confusion. ${ }^{6}$ The driver greets the dispatcher (line 3 ) and immediately following this (also line 3 ) comes a likewise formally prescribed form of identification where the driver states his position ("driver") and the identification number of the train of which he is in command. This is required in order to make sure that the dispatcher does not mistake the driver for a driver of another train or for other service personnel. Even though the dispatchers can see the locations of various trains within their region on a huge panel on the wall, they do not automatically have access to information about which train a certain phone call comes from. Thus, both parties self-identify by what Zimmerman (1992:452) has called categorical identification, naming their professional function (the train dispatcher being on duty at "the remote in Newbury", line 2); nobody gives his personal name in the opening sequence. Irvine (1979:778) also discuss this kind of identification, terming it "positional identities" in contrast to personal identities, and points out that it is a common feature of formal interaction. The dispatcher reciprocates the driver's (informal) greeting (line 4), and at this point the opening sequence is completed.

The driver then states his reason for calling (line 5): an arrival notification to the dispatcher, because the train driver is now entering an automated region ("Oaktown") controlled from the regional line control centre. These are routine matters, occurring every time a train reaches this location on this route. The dispatcher repeats the message given by the driver in the previous turn (line 6), in accordance with the rule book which states that important information which may have consequences for safety issues should be repeated in order to avoid misunderstandings. After a short

\footnotetext{
${ }^{6}$ An informant at one of the line control centres has confirmed that it sometimes happens that a driver calls the wrong line control centre.
} 
confirmation ("yes") from the driver (line 7), the dispatcher "signs" the arrival notification by stating his personal name (lines 8-9). The driver also gives his personal name (line 10), as part of the signing procedure, and the dispatcher repeats the name of the driver (line 11). In contrast to the identifications in the opening sequence, the identifications given here are mainly concerned with who are personally responsible, rather than specifying which train this call is about or who is calling. However, also in this case the form of signing follows the prescribed format. The following turns (lines 13-17) enact the closing of the call without any specific formally prescribed features.

There are also a number of informal features in this call, that is, adjustments to the particular situation at hand, motivated by other needs than safety considerations or formal adherence per se. The driver's "hi" (tjena) (line 3) is very informal (more so in Swedish than in its English translation) and has a relational and colloquial character. This is not to claim that we necessarily have a relation between close acquaintances; the use of this colloquial style is simply a conversational format of 'doing being personal'. This holds for the train dispatcher's "hi there hi" (hejsan hejsan) too (line 4). Other informal features are the final "yeah" ( $j a$ ) in lines 6 and 9-11, "thanking so much" in line 8, the driver's insertion of "at last" (äntligen) in line 5 and the dispatcher's repetition of this in line 6. In contrast to the formal, partly anonymizing aspects described above, these features have affiliative functions such as achieving and sustaining mutual trust and the use of "at last" (lines 5 and 6) shows an orientation to the common goal of achieving smooth and efficient traffic.

As stated, the example presented here shows a routine task and despite the informal elements it exhibits a more or less exemplary progression according to the prescribed sequence and form. It is important to note that the regulations are not detailed enough to cover each and every utterance which is supposed to occur. The identifications in the opening sequence have the correct form, the arrival notification is labeled correctly, important information is repeated, and finally the message is "signed" by the participants, also according to the rulebook. However, as pointed out already, formality does not come by itself, no matter if it is routinized or not, since in one sense it has to be achieved in every new situation - "routine as achievement" (Schegloff, 1986). In this case, for example, "thanking so much" (lines 8-9) may potentially be problematic. Thanking often occur in these calls, but almost always as part of the closing sequence ("thanks", "bye"), rather than in the middle of transactional exchanges. For this reason the use of "thanking so much" on behalf of the dispatcher at a point in time which precedes the driver's signing is something that the driver will have to deal with. The use of $j a$ ("yeah") at the end of utterances like the ones in line 6 and lines 9-11 marks something as being expected, and the reason why the driver (line 10) copies the formula "here yeah" from the lines 8-9 may be precisely to indicate the expected nature of his signing at this point, despite the dispatchers "thanking so much" in the preceding turn. This demonstrates how informal, conversational, features may provide a method of achieving and establishing formally required elements.

Our second example shows other types of frequent informalizations. At issue, this time too, is an arrival report:

(2): TTC 127

1.

2. DISPATCHER: the remote Newbury

3. DRIVER: yeah the driver eighty-five zero six

4. DISPATCHER: hi there $d u^{7}$

5. DRIVER: hi there $d u$ arrived at Oldtown and Johansson

$6 . \quad$ on that

$7 . \quad(1.0)$

8. DISPATCHER: Johansson then you have got Nilsson here yeah

$9 . \quad$ thanks $d u$

10. DRIVER: yeah [thanks

11. DISPATCHER: [thanks bye

12. DRIVER: bye

$13 . \quad(($ click $))$

As pointed out before, arrival reports occur routinely on this route. The performance of these arrival reports is therefore routinized and subject to routine simplifications. Here, in contrast to the previous example, the driver

${ }^{7}$ The meaning of the Swedish pronoun $d u$ (literally: "thou/you") is explained below. 
collapses three different actions in his turn in lines 5-6: his reciprocated greeting, the reporting and the signing. This compression of many actions into one single turn has been described for institutional telephone communication by Zimmerman (1992), and Falzon (2006) has called the corresponding phenomenon in air traffic control talks "batching". Compressions tend to appear precisely in routinized lines of action.

Compressions sometimes become problematic from a formal point of view, since they tend to lead to omissions. In this case an omission can be seen on line 8 where there is no repetition of the message by the dispatcher (as in the corresponding sequence of example (1), line 6), but only of the last part of the compression, which is the driver's signature ("Johansson"). This prompts another compression; the dispatcher gives his own signature ("Nilsson"), and proceeds directly to thanking, which projects imminent closure. Again, the reply to the compression only replies to the last part, that is, the thanking, and repetition of the driver of the dispatcher's signature is omitted. However, despite these compressions leading to omissions, this does not seem to pose any kind of trouble for the participants, arguably because of the expected and routine character of this exchange.

Example (2) also involves a number of informal additions to the exchanges, embedding the prescribed parts of the utterances. There is, for example, once again the colloquial greetings (lines 4-5), here translated as "hi there" (hej du) (lines 3-4). In this case they involve a final $d u$ (literally: "thou/you"), addressing the listener, which is very informal (in the everyday sense of the word). (The phenomenon is somewhat similar to the frequent use of first names at the end of utterances in certain American conversational styles). In our case, these items often appear in an unstressed form $(d \ddot{o})$, The final $d u$ also appears in line 8 (cf. also the final "yeah" ( $j a$ ) in line 8; cf. (1): lines 6 and 10-11, above). There is also an example of a colloquial and conventionalized variant of a prescribed format (line 5): "on that", as if the driver puts his personal "stamp" on the report.

A more advanced case of compression that causes an omission is visible in the third example, again a driver's arrival report:

\section{(3) TTC 97}

1 .

2. DISPATCHER:

((telephone rings))

3. DRIVER:

4.

the remote Newbury

yeah hi this was the driver on eigh- eighty-seven

5. eighteen then it was arrival report in Oldtown an'

my name was Johansson

6. DISPATCHER: Johansson there and Nilsson here $d u$

$7 . \quad(0.5)$

8. DRIVER: Nilsson?

9. DISPATCHER: yeah

$10 . \quad(0.5)$

11. DRIVER: yeah thanks

12. DISPATCHER: then we say thanks for that

13. DRIVER: $\mathrm{mm}$ [bye

14. DISPATCHER: [okay

$15 . \quad$ ((click))

The driver's compression of at least four constituent actions in his first turn (lines 3-5) makes the greeting and acknowledgement from the dispatcher no longer conditionally relevant, causing omission of these in the repetition (line 6), in addition to the omission of a repeated message as in example 2. The usual slots for the dispatcher's greeting and a confirming response to the driver identification, as well as the repetition of the message, are all cancelled. Again it seems as if the opportunity to make a specific kind of contribution (which must be made in a specific phase or sequential position) is bypassed and respondents do not provide it in a delayed position; the turn following the compression hooks on only to the last part of the compressed "batch", in this case too. Even though these responses to the last constituents of compressed constructions can be interpreted as a form of implicit overall acceptance of what was said, they do not provide an overt manifestation of how the respondent understood or heard what was said. In this routine case though, the omissions do not have safety-critical effects.

Let us now turn from arrival notifications to the issuing of orders by dispatchers. The agenda concerns the delivery of an order, which in many cases requires the filling in of a pre-printed form, which must be completed as 
documentation of certain changes in the train traffic, primarily serving as an explicit memory aid for the driver during the trip. Regarding the communication, the form also comes to function as a visual reminder, structuring communication. Here, the meeting with another train at a certain station ("Danby") will be dispensed with:

\section{(4) TTC 68}

1.

2. DISPATCHER:

3. DRIVER:

4. DISPATCHER:

5. DRIVER:

6. DISPATCHER

7. DRIVER:

8. DISPATCHER:

9. DRIVER:

10. DISPATCHER:

11. DRIVER:

12. DISPATCHER:

13.

14. DRIVER:

15. DISPATCHER:

16. DRIVER:

17. DISPATCHER:

18. DRIVER:

19. DISPATCHER:

20.

21.

22.

23.

24.

25.

26.

27.

28.

29.

30.

31.

32.

33. DRIVER:

34. DISPATCHER:

35. DRIVER:

36. DISPATCHER:

37. DRIVER:

38. DISPATCHER:

39. DRIVER:

40. DISPATCHER: ((telephone rings))

the remote in Newbury

$\mathrm{mm}$ yeah ninety-five forty-five

yeah hi there (.) [hi

[hi

then [let's see

$\left[\mathrm{S}\right.$ sixteen you said $^{8}$

$\mathrm{S}$ sixteen yeah exactly=

$=$.yeah

the back side there then ${ }^{9}$

the back side

yes $(0.5)$ for train ninety-five forty-five

then yeah

yes

today's date zero four zero three seventeen=

$=<$ zero four zero three seventeen $>$ ((self-dictating voice) $)$

then we hop down to uh section twenty-one there

twenty-one yes

yes and Bravo ${ }^{10}$ then the K-meeting ${ }^{11}$

with train ninety-five eighty-two ninet-

ninety-five seventy-six

$<$ ninety-five seventy-six $>$

in Danby drops off

$<$ yes $>$

that will be cancelled today there so

yes exactly

(0.5)

then it's for train ninety-five forty-fi::ve zero

four zero three seventeen and then twenty-one B

(.) ninety-five seventy-six in Danby drops off

that's correct yeah the time is thirteen zero

four then an' my name is Olsson

$<$ Olsson $>(0.5)$ my name is Eriksson

Eriksson yeah

$\mathrm{mm}$

thank you so much there yeah

thank you too

yeah okay=

=bye

bye

((click))

\footnotetext{
8 "S16" is the name of the form.

${ }^{9}$ Referring to the back side of the form sheet.

${ }^{10}$ The term "Bravo" is used to refer to the letter " $\mathrm{B}$ ".

11 "K-meeting" is a formal term for meeting another train at a station on a single-track section.
} 
After the opening phase, the agenda is established through the naming of the pre-printed form ("S16") (lines 7-9). The dispatcher then starts delivering the order and the sequential order of the pieces of information given by the dispatcher follows the structure of the form. The driver, the receiving party, copies the information into her blank. While doing so, she repeats (or acknowledges) the dispatcher's information directly after each utterance, one after one (by installments, lines 11, 16, 18, 22), often as part of writing this information in the form. ${ }^{12}$ This kind of repetition will be termed direct repetition here. After this, the dispatcher informally summarizes the gist of the whole message (line 25). The driver then makes a complete repetition in one single turn (lines 28-30), what will be termed a summarizing repetition here, evidently by reading back aloud what has been written down. Thus, there are two kinds of repetition in play here. The summarizing repetition is prescribed in the rulebook whereas the direct repetitions are not. This means that when the sequential position for a summarizing repetition is reached, most of the information is already repeated once through direct repetitions. Despite this "redundancy", the summarizing repetition is in most cases still quite complete and this is clearly due to the formal structure of order deliveries, and the use of a form supports reading back what has been written. In sum, the form structures the sequential ordering of the conversation, helping the participants to remember all steps and also to repeat them. After the summarizing repetition the dispatcher confirms that the summarizing repetition was correct and gives the time of the day (lines 31-32), which is also according to the rulebook. (There is a slot on the S16 where the driver has to write the time when the order was confirmed.)

In the next example, the S16 form is the source of both informalization and formalization:

(5) TTC 158 (lines 1-2 are the start of the second order of two orders in the same call)

1. DISPATCHER: uhm and uh then we take Sandhill and Newhaven (0.5)

2. $\quad$ section twelve train may leave without train order

3. DRIVER: twelve A train order nil there too right

4. DISPATCHER: that was correct an' Svensson on that too $d \ddot{o}$

5. DRIVER: an' Svensson Johansson here [yes on that

6. DISPATCHER: [yeah good

7. DRIVER: fourteen thirty-two yeah

8. DISPATCHER: yeah thanks thanks

9. DRIVER: $\quad$ good

10. DISPATCHER: good

11. DRIVER: fine

12. DISPATCHER: bye

13. DRIVER: bye

14. ((click))

In this case, the order given is the second out of two almost identical orders given in the same phone call. The only difference between the current order and the previous order is the direction of the line section (Sandhill $>$ Newhaven vs. Newhaven $>$ Sandhill). In such cases, the handling of the second order is almost always considerably more compressed than the handling of the first, due to its expected and "repeated" nature. In this case, the whole order is given in one turn (lines 1-2). Furthermore, what form to use is part of common ground, since it has already been established in connection with the previous order, and there is no need to say it again. The kind of order given here only requires writing of "Sandhill" and "Newhaven" and the rest of the information (what section of the form which applies, and "no train order") is noted through ticking off slots and whenever that is the case there is usually less direct repetitions of the kind we saw in the previous example when the driver was writing. The summarizing ${ }^{13}$ repetition by the driver (line 3) consists of naming the section on the form ("12 A") and the rather formal term "nil" (intet), but no explicit mention of the line section "Sandhill" and "Newhaven", which is already common ground since the previous order ("there too", line 3). After this, the dispatcher gives another compressed turn, confirming the presumed correctness of the driver's summarizing repetition and then proceeding directly to signing, but omitting the time stamp which is an obligatory part of the signing procedure at this point (line 4). It is not only the case that the absence of the

\footnotetext{
${ }^{12}$ The act of writing is often hearable in the slow-paced pronunciation of the repetitions in these cases.

${ }^{13}$ In this case our distinction between direct repetitions and summarizing repetitions is blurred, since the order is given in a single turn and the summarizing repetition comes "directly".
} 
time stamp stands in contrast with the formally prescribed sequence; it also contrasts with the sequential layout of the other calls in our corpus. After the signing sequence (lines 4-5), in which the dispatcher does not repeat the driver's name, the dispatcher initiates the closing of the order delivery by an evaluation (line 6). Again, the compressions and omissions in this example seem to be due to the fact that this order is the fourth one in a series of almost identical orders in the same call. It could be argued that the use of a form is not just a formal device, but simultaneously (partly) a source of informalization here, since it makes the delivery of a series of similar orders highly repetitive due to some information (train number, which form to use, time of day, signatures) being the same for each order.

However, forms may also support the detection of omissions and prompt their repair. In this example, the time of day is not present in the compression (line 4). This is repaired somewhat belatedly by the driver, who inserts a note of the time (line 7) after signature names have been exchanged (although the dispatcher is normally supposed to provide this information). This amounts to compensating for a previous omission and reshuffling the formally prescribed sequential structure. If we take this as a kind of repair, it occurs in the fourth turn (line 7) after the repair source (line 4), the last position for doing it (Schegloff, 1992). The final "yeah" ( $j a$ ) (line 7) seems to mark the piece of information as a previously missing item. The dispatcher acknowledges this (line 8: "yeah"), and then proceeds into the closing sequence by thanking. Providing a missing item in this sequence is managed much like in a private conversation. The "skip-connecting" (Broe, 2003) is again caused by compression, but whereas the conditionally relevant position for giving the time of day in the talk exchange is passed, the driver is prompted for this missing information by the form lying in front of him.

Another kind of deviation from "conversational discipline" is what might be called time-out talk. Some calls contain fairly extended time-out episodes (see Linell, in press, for an example), but due to space restrictions we will just give a short example here:

(6): TTC 80 (first turns omitted here)

5. DISPATCHER: hi there $d u$ I have an order delivery for you $d \ddot{o}$

6. DRIVER: yes

7. DISPATCHER: on S sixteen there then

8. DRIVER: $\quad \mathrm{i}:: \mathrm{a}::$ : must reach the bag there

9. DISPATCHER: he he he

10.

11. DISPATCHER: long arms $d \ddot{o}$

12. DRIVER: long arms one must have

$13 . \quad(2.0)$

14. DRIVER: and wet fingers

15. DISPATCHER: yeah. he hehe

16. DRIVER: we shall see if we find a pen

$17 . \quad(1.5)$

18. DRIVER: $\quad$ rattata $(($ singing $))$ tricky it was $d u$

19. DISPATHER:: yeah

20. DRIVER: let's see then for train of course right

21. DISPATCHER: exactly train ninety-five twenty-four then

$22 . \quad(1.0)$

23. DISPATCHER: today's date zero four zero one thirteen (.)

$24 . \quad$ thirteen

25. DRIVER: <zero four zero one thirteen $>$ (.) $\mathrm{so}=$

((filling in of S16 proceeds))

Lines 8-19 constitute a side sequence, which is a commentary on a subsidiary activity; the driver must find his bag and pen and wet his finger to be able to pick out the form from the bag. Such a sequence is, by definition, not taskincluded in a narrow sense, but it is still ancillary to the task of receiving the order, i.e. it is task-related. In this case the side-sequence provides the accountability of the gap in the main activity. It develops tangentially from task-included talk (line 8 does not occur abruptly but is a response to the preceding talk), it involves both participants, and it is ended by an abrupt return to the main activity (line 20). Talk that is not even task-related is very rare in the corpus. 
Impromptu time-out talk seems to be a harmless deviation from the formal code, at least in the data available for analysis here. It is characterized by other kinds of prosodic orchestration than transactional and formulaic talk; it tends to be different in terms of intonation, rhythm, pace, and articulation style (hyper- vs. hypo-articulation). You can hear such differences when the dispatcher is dictating and the driver doing repetitions, as compared to when they are talking off the cuff. Non-transactional talk is thus (perhaps inattentively) marked off as outside of the safety-critical framing (cf. also Westerholm and Åström, 2003).

In sum, informalization often takes the form of informal additions embedding of prescribed parts of utterances, colloquial variants of the prescribed formats, and side sequences. It also takes the form of compressions, regularly causing omissions that remain un-repaired. Rules provide a major resource for the achievement of formality, and so do pre-printed forms, which provide reminders and a resource for structuring the conversations. In the cases analyzed though, the informalizations are not troublesome: sometimes they are compensated for but in most cases the omissions still do not have any critical effect because they occur in routine and well-structured situations where they can be contained through recourse to expectations of routine structure of the talk and familiarity with the situation at hand.

\section{Analysis of informalizations causing a near miss in a non-routine situation}

In this section we identify some informalizations that caused a near-miss incident in an unplanned situation (Banverket, 2004). Misunderstandings were caused by the combination of informalizations, an underdeveloped terminology for common trouble-shooting and situational features such as improvised routes, low audibility and stress. Our case concerns a train driver, who is testing a railcar and who has later received a new order to fetch and tug away a train that has broken down at the local station of Stonehill. The dispatcher and colleagues, together with the driver and the train operating company, have to troubleshoot a solution, improvise routes, find means to evacuate the passengers from the broken train as well as permitting other traffic to pass the station with a minimum of disturbances in the overall traffic flow.

Since the broken train is parked on the station, the signals around it are set to stop to protect it from collision. To fetch the train, the railcar needs to move to the other side of these signals. There are two types of signals involved, running signals (main signals, huvudsignal) and ground signals. The former are used for train routing while the latter are used for shunting, i.e. used for local movements over the yard. Ground signals are physically smaller (lower), and the Swedish term is in fact (literally) "dwarf signal" (dvärgsignal) or just "dwarf" (dvärg). Running signals have names like "Stonehill 21", that is, both the station name and a number, while ground signals just carry numbers, such as " 81 ". This difference will play a decisive role in the conversations below. When the driver makes the first of a series of problematic calls (preceded by non problematic calls), he has got a red light on the entrance running signal Stonehill 21. Such a red light is also called "signal at danger" (signal $i$ stopp), meaning he needs to stop the train. To pass a signal at danger, he needs the dispatcher's explicit and formal permission:

\section{(7) TTC:BV1}

1.

2. DISPATCHER A:

3. DRIVER:

4.

5. DISPATCHER A:

((telephone rings))

the remote Newbury

okay chee- (.) I'm on my way, now I am at

Stonehill 21 at danger here

6.

7. DRIVER:

yes ((sigh)) we say that 59334 may pass

St- (.) may pass Stonehill 21 at danger then

yes

8. DISPATCHER A: and Magnusson on that

((a six turn side sequence omitted))

15. DRIVER:

okay then 59334 will pass Stonehill 21 at danger

16.

17.

18. DISPATCHER A: ((speech in the background)) the switches are set and $\left[(\mathrm{x}){ }^{\circ}\right.$ like that ${ }^{\circ}$

[yes

19. DISPATCHER A:

20.

yes $=>$ hold on then $<$ it's like this y'know, you

will have a signal at danger there in the

21.

dwarf there (.) the 81 then 
22. DRIVER:

23.

24.

25. DISPATCHER A:

26. DRIVER:

27. DISPATCHER A:

28. DRIVER:

29.

30.

31.

32.

33.

34.

35.

36.

37.

38.

39.

40.

41.

42.

43.

44.

45. DISPATCHER A:

46. DRIVER:

47. DISPATCHER A:

48. DRIVER:

49. yeah I can see all the way up to him I see

him standing [in there

$$
\text { [yeah }
$$

cause there you'll have to wait a little bit

ther- $(\mathrm{xxx})$

cause I must put some trains through he[re

\section{[it}

crackl- (xx xx xx) -ibly here

(.)

you have to wait there cause I'll run an

$\mathrm{X} 2$ ((an express train)) run before I can

let you in towards the other one there

yes

by the 81 then

yes yes I'll go- can can I go towards the

other I didn't hear what you [said, cause

[yes

it's crackling that much [you see

$$
\text { [yeah }
$$

yes go up to the 81 and you will get

a signal from there then

(.)

yes yes

yes that's good

I push on towards him then and we'll see

yes that's good bye bye

okay bye

((click))

This is not the first call exchanged between dispatcher and driver, which may account for the absence of the driver's identification (line 3). Otherwise, the first part of the talk is relatively formal and not problematic. The train dispatcher issues an order (lines 5-6) in a compressed form (with the signing on line 8). The order contains a permission to pass a home signal ("Stonehill 21"), despite the fact that it shows red light aspect ("at danger"; line 15). The home signal is a running signal that is passed when entering the station from the line. The driver repeats the order in the formally prescribed way (lines 15-17).

It is after this that the problems start with semantically ambiguous prepositions and unclear references, no repetitions and no formal acknowledgements, reinforced by problems of audibility. The driver is also apparently more focused on his task to tug the other train away than listening to the dispatcher. On the other side of this home signal, there is a switch ground signal ("81"), and the train dispatcher instructs the driver to wait before passing this signal (lines 19-21, 25). However, the driver does not respond to that; instead, he starts to talk about the other train (lines 22-23: "I can see [...] him standing [...]"). This is the train that the driver is going to pick up, and it is standing further away at the station, beyond the ground signal. Further on, the telephone exchange is impeded by technical problems. Evidently, the driver cannot hear the dispatcher properly, and the driver complains several times about this ("crackling" noise; lines 28-29, 39). ${ }^{14}$ In addition, no proper issuing of orders with repetitions takes place. The dispatcher informally repeats the message that the driver should proceed up to ground signal 81 (lines 41-42), but the driver seems to continue his talk about "the other" (train) (line 3637). In fact, the driver never mentions ground signal 81, although the dispatcher does so repeatedly (lines 21,35 , 41). When the dispatcher states the order once more (informally) (lines 41-42), there is again no repetition from the driver. In fact, in most cases the driver only gives acknowledgements and claims of understanding (lines 34,

\footnotetext{
${ }^{14}$ According to the rules, communication should be stopped under conditions like this, and parties should wait until the problem is gone or other means of communication have been found.
} 
44: "yes" and "yes yes"), but no proper repetitions making that would make his actual understanding of the order explicit.

A few minutes later the driver calls the dispatch centre again. The call is taken by another train dispatcher (B):

\section{(8) TTC:BV2}

1 .

2. DISPATCHER B:

((telephone rings))

3. DRIVER:

the remote Newbury

4. DISPATCHER B:

oh now there's another voice okay

5. DRIVER:

yeah.

6. DISPATCHER B:

7.

8. DRIVER:

9.

10. DISPATCHER B: yes in the 21 yeah

it's 59334 here you know

yeah you drove against stop there yes,

in the 81

ye:s y'know I got permission to go

against signal at danger

11. DRIVER: yes and then she talked about the dwarf

12. DISPATCHER B: yeah there you should stop yes

13. DRIVER:

14.

o:h I took it that I got permission to

go against signal at danger

15. DISPATCHER B:

no no no (.) [you must you must enter=

16. DRIVER: [( $\left.\left.\begin{array}{llll}\mathrm{x} & \mathrm{x} & \mathrm{x} & \mathrm{x}\end{array}\right)\right]$

17. DISPATCHER B:

18. DRIVER:

$=$ the northbound track

yes I know that of course

((a side sequence of about 35 lines has been omitted, in which the driver explains in a rather agitated way that he had been confused, he was not able to hear, the line is still bad, etc.))

54. DRIVER:

cause no: we got damn confused here=

55. DISPATCHER B:

=okay, now you do like this

56.

I must run let $255^{15}$ drive past in any case

57.

you change ends ${ }^{16}$ so so or else you will

58.

have to wait like hell if we do it in that

59.

direction so change ends and put yourself

60.

61.

62.

DRIVER:

in front of Stonehill 62 and when you stand there

you give me a call again then

63. DISPATCHER B:

ehr::::m shall I go back you mean?

64.

65. DRIVER:

I think so cause I must get 255 through and

while he drives past there you can do that

okay yeah

66. DISPATCHER B:

cause then comes a commuter on the other side

67.

68. DRIVER:

in any case you see

69.

70. DISPATCHER B yes yes yes okay then then we go back to that

then

72. DISPATCHER B:

73. DRIVER

yes do that $d \ddot{o}$

okay

good

bye

74. DISPATCHER B: bye

75.

((click))

15 " $255 "$ is the express train mentioned in (7): line 32.

16 This means that the driver should walk over to the cabin at the other end of the railcar so that he can drive in the opposite direction. 
This call is caused by the driver's misunderstanding and mistaken action, resulting from the previous call. The opening of the call deviates from the norm; the driver reacts by saying "now there's another voice, okay" (line 3), which, however, makes him give his train number this time, although somewhat belatedly (line 5). Due to a misunderstanding in the previous call, he has passed a signal at danger that he had no permission to pass. There is a fair long sequence (omitted here) in which the driver tries to exculpate himself, and the dispatcher asks him to calm down. In the end, the dispatcher issues a new instruction (line 55: "now you do like this"). The driver has to drive the railcar in the opposite direction, and this time he has to drive up to a running signal called "Stonehill 62". Again, there are no repetitions made and the acknowledgements are rather minimal (lines 65, 68). Six minutes later this is followed up with a new call between the same parties:

\section{(9) TTC:BV3}

1.

2.

DISPATCHER B:

((telephone rings))

3. DRIVER:

the remote Newbury

4. DISPATCHER B:

yeah cheers it's Olsson again here then

5. DRIVER:

yes

6.

now I'm standing by the 62 here, and now

I can see 255

((about 7 lines omitted, the dispatcher makes a break to take another phone call, and then comes back:))

14. DISPATCHER B: what's his position there in $\mathrm{u}:: \mathrm{h} 3195^{17}$

15. DRIVER:

16. DISPATCHER B:

17. well he is standing at the very Stonehill [station

[yeah do

18.

19. DRIVER:

do you get inside the running signal directly when

you move towards him later

20.

I don't dare to answer that cause I don't didn't

see cause that close I didn't get it's pretty far

21. away from where we were standing and then-

((about 15 lines omitted; talk about various problems with 3195))

37. DISPATCHER B: okay let's say like this that u:hm the train set

38.

from 59334 then (.) is granted permission to

39.

40.

41.

42.

43. DRIVER:

pass Stonehill 62 at danger then and then

a dwarf signal at danger and the switches

lie right towards the down track side and

Persson here then

44.

45. DISPATCHER B:

oka:y then we pass with train set 593 (.) what

the hell bah where am I now 59334 I'm called

46. DRIVER:

$\mathrm{mmm}$

47. DISPATCHER B:

Stonehill 62 at danger and the following dwarf then

48. DRIVER:

49. DISPATCHER B:

50. DRIVER:

51. DISPATCHER B:

yes exactly

yes it's enough I suppose if I cross the switches?

well [ehrm

[or do you want me to pass in[side

52.

53.

54.

DRIVER:

[then you must

set them yourself you must go and park behind

Stonehill 81 then

((a few more turns before the conversation is brought to an end))

Here we get a fairly normal order-giving sequence, for the most part according to the book but with some informal features (lines 37-46). However, it turns out that some things remain unclear; among other things, the dispatcher

\footnotetext{
$\overline{17}$ This is the train that the driver should pick up.
} 
informally instructs the driver to stop "behind Stonehill 81". This additional instruction is delivered in a short sequence with some overlapping talk. As we shall see, new problems will emerge.

About 2 min later the driver initiates a new call:

\section{(10) TTC:BV4}

1 .

2. DISPATCHER B:

3. DRIVER:

4. DISPATCHER B:

5.

6.

7. DRIVER:

8. DISPATCHER B:

9.

10.

11.

12.

13.

14.

15.

16.

17.

18.

19.

20.

21.

22.

23.

24.

25.

26.

27.

28.
DRIVER:

DISPATCHER B:

DRIVER:

DISPATCHER B:

DRIVER:

\section{DISPATCHER B:}

DRIVER: ((telephone rings))

the remote Newbury

yes it's Olsson here again

((agitated voice:)) what the devil Olsson now

you went against stop in the 72 too what are

you up to?

((incredulous voice:)) I didn't did I?

you bloody hell did you are out on the line here

9334 had an emergency stop here just because of

that I mean we are just lucky that he's not on

the block section there ${ }^{18} y^{\prime}$ know

whe:re do you mean?

inside on- you (.) are passing the station limit

bloody hell you cannot- you mustn't do that

without permission you have to pass one- one

main signal plus a dwarf signal you cannot pass

the exit signal ${ }^{19}$ at danger ((sighs))

((a couple of seconds of silence))

I see $d \ddot{o}$ [it's

[now we are going to stall [you

[yes

you mean the 81 here yes that one I will pass

here now (.) now put me aside

yes (.) yes we'll have to wait here now

now I've got three more calls here $d \ddot{o}$ move

aside and stay there for the time being $d \ddot{o}$

yeah okay

$\mathrm{mm}$ bye

The driver has not only passed the running signal "Stonehill 62" (and a ground signal), he also passed by yet another ground signal, no. 81, that he was supposed to "park behind" (excerpt (9): lines 52-53). What is more serious is that he also passed Stonehill 72, the running signal ("exit signal", line 17) at the exit of the station. This means that he has ended up "on the line" (line 8), technically being outside the station. Being out on the line he could have clashed with another train; the dispatcher mentions "9334" which had an emergency stop (line 9). As we can see, the last phone call is rather emotional, and the new instructions are passed on without any formal order giving (lines 2024). The dispatcher is apparently stressed and the driver probably scared. However, this does not impede the parties from inserting some colloquial dö's (lines 19, 25-26) of the sort that we have seen before.

The informalizations in several passages of these calls went beyond colloquial variants of prescribed formats into something more akin to private conversation. In the first call, the instruction concerning whether to pass ground signal 81 was neither formally given nor were problems of potential misunderstanding resolved. The problems were aggravated by technical problems with the phone line, leading to hearing difficulties. To some extent the two parties were talking about different things, which led to a misunderstanding as evidenced by the second call. The driver seems

\footnotetext{
${ }^{18}$ I.e., the same segment of the line.

19 This is the signal that trains pass by when leaving the station and entering the line. The proper English term is "starting signal", but the Swedish term used in the excerpt is utfartsblock(en) (Eng. "(the) exit blockings"). To preserve the perspective of the Swedish term, this has been translated as "exit signal" here.
} 
to have had the other train in mind (excerpt (7), BV1: lines 22-23), and this may also apply to lines BV1:36-37 ("can I go towards the other?") in the same call. The dispatcher rather talks about the ground signal (81), and tells the driver to "go up to" this (line 41), which was intended to mean that he should stop before the signal. The driver, however, concludes that he should push on towards "him", presumably the other train (line 46), which in reality would mean passing the ground signal 81 . The dispatcher may not have reacted to the driver's use of the word "him" in this case, perhaps due to the fact that the ground signals are called "dwarfs" in Swedish. Thus, the sequence is replete with pronouns ("there, him, the other") and prepositions ("up to", "behind", etc.) with unclear references.

The most serious problems, as evidenced in the fourth call, arise from the third call. Again, some instructions, added on in a sequence following the main order, were given informally. The dispatcher's "go and park behind Stonehill 81" ((9), BV3: lines 52-53) is ambiguous, as Banverket's incident investigator points out in his report (Banverket, 2004): the dispatcher misleadingly says "Stonehill 81 ", when the convention is to use naked numbers about ground signals, and the preposition used ("behind") might also be understood as "on the other side of" rather than (as intended) "before coming to". These verbal circumstances may have contributed to the driver's mistake to pass another running signal, that is, the exit signal 72.

In sum, informalizations such as the use of unclear references and ambiguous prepositions in combination with low audibility produce several misunderstandings that cause the driver to repeatedly pass signals at danger without permission. We would also hypothesize that the failures in the conversation is due to the conflation of the troubleshooting procedure of fetching the broken train with the safety-critical communication needed to do this. Both the train driver and the dispatchers involved were focused on the trouble caused by the need to tug the broken train into a repair unit. A solution was improvised based upon the specifics of the situation and previous experiences of fixing troubles. The route towards the train and the means to get there were regarded as side issues.

\section{Conclusions: "Conversational discipline" and a contingent theory of informalization}

Theoretically, we might think of train traffic control calls as interactions in which parties are subject to a "communicative dilemma" (Adelswärd, 1988). A dilemma is a situation in which there are competing and opposite demands, which means that none of them can be fully satisfied in any workable solution: a compromise is necessary. In our case, certain critical information must be communicated and made into common ground. Under the time constraints that hold and with the restrictions of talking over the phone (or radio or similar media), this may call for formality in the sense defined in section 3. On the other hand, this communication is conversationally implemented, and therefore necessarily prone to adopt social-relational and other functions as well. We are also faced with routines which are acted out again and again, and yet each enactment is to some extent an achievement (Schegloff, 1986); a kind of problemsolving sensitive to various situation-bound factors (such as the individuals involved and their social relations). All in all, these other functions of the communication may engender, or call for, certain kinds of informality. The situation therefore invites participants to make some kind of compromise, to strike a balance between formality and informality.

Formality in safety-critical communication is a theoretical problem for discourse analysts but also a practical problem for the participants. The practical problem in train traffic control has its counterpart in a "members' notion" which is also a source of formalization, namely, that of "conversational discipline". Participants have to adhere to some form of "discipline" in order to guarantee an adequate information exchange. At the same time they do not always live up to the prescriptions of the rulebook; they cannot avoid some aspects of informalization. In a talk between two people, it is hard to keep conversational logic completely out. Another reason for informalization may reside in the nature of routinization itself; everything goes well in the vast majority of cases, and this may seem to imply that there is room for informalization.

We have seen examples of several different types of informalization. Let us summarize their forms, and then discuss their implications for the activities involved. Our analyses suggest four categories of informalization in TTC calls:

A. Normal informal embeddings of formally required, transactional parts: minor lexical additions, and coping with speech errors and hearing or comprehension difficulties (repairs, corrections).

B. Colloquial form(ulation)s (variants) of required transactional parts; there seems to be an informal (sometimes jargon-related) tradition of carrying out the formal.

C. Omissions of formally required (organizationally regulated) parts.

D. Addition of non-transactional material. 
If we categorize our TTC calls in terms of McCarthy's (2000) categories, we can conclude that, in addition of course to transactional talk, we find "transactional + relational" and "relational", but not "phatic" talk. ${ }^{20}$ McCarthy would have classified all four categories A-D as transactional-plus-relational and relational. Let us dwell for a while on these four phenomena, one by one.

First, (A) seems to occur whenever a transactional or even formal task is carried out in a spoken exchange between human beings. For example, it occurs frequently in the actual staging of standardized survey interviews, which, in theory, should be carried out identically across instantiations (Houtkoop-Steenstra, 2000; Maynard et al., 2002; Stax, 2004). The exact ways in which formally prescribed talk is actually carried out are always dependent on the locally occasioned and individually motivated detailing of the performance. Personalizing features leak into the actual utterances. They are a kind of social "lubrication". Here, we have seen it in, for example, the use of final $d u / d \ddot{o}$. They deviate from strict formality but are not problematic to safety.

(B) is also quite widespread across talk activities, except in strict ceremonies. Particular communities of practice (Wenger, 1998) develop more or less local professional jargons and colloquial forms. Similar phenomena occur in most professional activity types, even in such scripted types as court trials. For example, in the Swedish criminal court trials studied by Linell et al. (1993), the judges' asking for the defendant's stance was often expressed in wordings like "and what do you say to that?" (å va säjs om de?) instead of, for example, "how do you plead, guilty or not?". However, Linell et al. argue that these colloquial forms are made possible because they always occur in the right slots in the whole activity sequence. The same phenomenon appears in our TTC calls, and they work for the same reasons; we have seen, for example, "Johansson on that" instead of, say, "signed Johansson". This occurs in a position when signing is due and is therefore inferred.

Akin in function (rather than form) to the (B) phenomena just mentioned are (minor) compressions due to routinized simplification, and the addition of some affiliative utterances, like thankings, colloquial address terms, the exchange of minor favors, etc. Similar deviations from the script occur in air traffic control, as documented by Sanne (1999) (cf. section 2). The data shows that train traffic calls talks are more like talk in e.g. air traffic control than one might think: there are compressions, omitted information, exchange of favors, creation of trust, etc. One may conclude that (B) is entirely acceptable, at least as long as the colloquial forms are conventionalized and occur in the right predefined slots. They deviate from strict formality but are not problematic to safety.

Category (C) comprises more ostensive omissions, that is, omissions of obligatory actions in prescribed sequences. In most cases, they result from (extensive) abbreviations and compressions. It is here that we find potentially harmful informalizations.

Category (D), finally, implies moving into tangential talk. However, it occurs mostly when there is time available for a time-out, while waiting for task-related events to finish. In our data, we have, among other cases, the train driver waiting for a signal (e.g. green light), or waiting for the computer to respond to a request. ${ }^{21}$ We noted above that such side sequences or time-out talk tends to be prosodically marked as different from transactional talk. In the case of the train which passed several signals at danger due to misunderstandings, it should also be noted that side sequences consisted in giving accounts of why certain things happened, and it might be argued that such accounts are not irrelevant, especially given that TTC calls is the only occasion for train drivers and dispatchers to talk to each other. We conclude that there is no evidence here that side sequences would be harmful per se, provided that the channel is not kept occupied unnecessarily.

Having summarized the forms of informalization, let us now have a look at their functions. Three points could be made. First, some simplifications may be motivated in terms of conversational efficiency. A strict adherence to a prescribed sequence of distinct, formally elaborated contributions would appear to be redundant. This applies to some compression of sequences. For example, in (5), where several similar orders were given in the same TTC call, there was a lot of compression and omissions - presumably due to the redundancy of the repeated information. Other examples can be found in the highly recurrent arrival notifications, such as in (1) and (2), where there was also a lot of compression and some omissions due to their routine character.

\footnotetext{
${ }^{20}$ This is a clear difference with respect to hairdressers' and shop assistants' talk with customers (McCarthy, 2000; Tykesson-Bergman, 2006). There are of course several differences also in circumstantial conditions between TTC calls and these other conversations; for example, the latter were not carried out over the phone.

${ }^{21}$ McCarthy (2000) pointed to the need for filling pauses in main activities with talk, for example, while waiting for something extra-verbal to happen, e.g. hair-dresser waiting for the hair to dry up, or the driving instructor and client during driving lessons waiting for a green light. TykessonBergman (2006) noticed the same phenomenon when shop assistants at the checkout till wait for the computer to respond.
} 
Secondly, there are also work-related reasons for making phone calls that have not been given a prescribed form in the written regulations but are nonetheless relevant for guaranteeing a safe or smooth traffic flow. These are problems and complications that must be solved more in a more ad hoc and exploring (in contrast to "routine") way. This may involve, for example, calling to inquire why a certain signal remains at "Stop" and how long it can be expected to do so. Here, there is of course more room for informalization. Non-transactional talk is not just a kind of unstructured "noise", or simply "carelessness" (cf. Garfinkel, 1967:192), polluting TTC calls and other types of institutionalized talk, but a consequence of some of the characteristics of the communicative activity type.

Thirdly, there may be a need for talking about matters of work and working relations that are consequential for smooth and responsible work in the long run, even if they are not part of the task at hand. This would be talk that is work-related (directly or indirectly) without being formally task-related. ${ }^{22}$

By way of conclusion, we suggest a re-specification of the notion of "conversational discipline". Since rigid adherence to formality is, at some level, not an option, one might suggest that a disciplined mixture of formality and informalization is what is desirable. Many practitioners would agree on this and they would argue that this is what they currently do. Probably this is what happens in most cases. However, the findings from the incident analyzed in section 6 indicates that the efficiency constraint have had more influence over how conversations are performed than the accuracy constraint, probably more so in train traffic control talk than in air traffic control (Morrow et al., 1994; Sanne, 1999). Moreover, we have seen how compressions might lead to omissions of important exchanges or confirmations, which in turn might potentially cause mistakes or wrong actions because of missed opportunities for repair work. As shown in our examples though, having a form as a visual reminder might help to repair omissions or mistakes and to retain the formally prescribed sequential structure of the talk (see also Halliday, 1994). Still, even formalization itself need not necessarily be innocent in each and every case. We have noted, for example, how formal treatment of several similar orders in the same call the order issuing highly repetitive, which often yields highly compressed turns in the issuing of later orders in such series of orders.

Thus, the interplay between the orientation to formality and informalizations is an outcome of both more conscious deliberations and the inescapable task of accommodating to the three fundamental requirements: safety, efficiency and sociability. It is a question of striking a balance. Practitioners regard the traffic control calls as a last safety barrier, in situations when dispatchers and drivers have no other communication systems to rely on. The empirical data suggest that the need for formality is enhanced under troublesome external conditions, such as stressful happenings and poor audibility. As the problematic events show, displays of correct reception and understanding of references and instructions are important especially under such circumstances. In those cases simple acknowledgements and mere claims of understanding (e.g. yeah, $\mathrm{mm}$ ), i.e. an omission of proper repetition, might lead to discrepancies between parties. In addition though, we suggest that there is also a need to improve both the means and skills to organize nonroutine situations and to clearly distinguish joint trouble-shooting and planning from safety-critical communication. A practice of self-evaluation and peer review, as used in air traffic control, is likely to improve reflection and practice.

Theoretically, we suggested contingent concepts that could distinguish between harmful and harmless informalizations, avoiding the "extremes" of, on the one hand, moralizing over harmless deviations from the formal code and, on the other hand, claiming that all informalizations are simply natural. The effects of informalizations seem to depend both on their nature and the situational context in which they appear. Some informalizations are harmless, especially if occurring in routine and familiar situations, whereas other informalizations may have dangerous consequences, especially when occurring in non-routine, improvised and often complex situations.

\section{Transcription conventions}

(.) micro pause

((abc)) comment on the character of the speech (contextual information is put in footnotes.)

(xxx) etc. denotes indecipherable speech

$a b c \quad$ Swedish, non-translated, word

$:$ denotes prolonged sounds

- $\quad$ interrupted speech

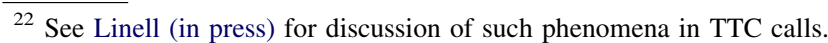


$=\quad$ on adjacent lines: no pause whatsoever between utterances

[ onset of overlapping speech

$<>\quad$ talk enclosed by these signs is spoken more slowly than the surrounding talk

.yeah speech during inhalation

\section{Acknowledgements}

We thank Erik Lindberg, deputy safety manager at Banverket, and two anonymous reviewers of Journal of Pragmatics for valuable comments on previous drafts of this paper.

\section{Appendix A. Supplementary data}

The original Swedish transcripts, with English interlinear translations, are available as supplementary data in the online version, which can be found at doi:10.1016/j.pragma.2009.05.022.

\section{References}

Adelswärd, Viveka, 1988. Styles of success: On impression management as collaborative interaction in job interviews. (Linköping Studies in Arts and Science 23.) Department of Theme Research, Linköping.

Andrén, Mats, 2005. Formalitet och informalitet i säkerhetssamtal mellan lokförare och tågklarerare. (Master's thesis.) Department of Theme Research, Linköping.

Atkinson, J. Maxwell, 1982. Understanding formality: the categorization and production of 'formal' interaction. The British Journal of Sociology 33 , 86-117.

Banverket, 2004. Obehörig stoppassage av dvärgsignal 81 samt av utfartsblocksignal N 72 i Vikingstad, 2004-10-06. Undersökningsrapport 2004:10:06.

Broe, Vibeke, 2003. Skip-connecting as a means for maintaining coherence - an aspect of the sequential organisation of talk. Acta Linguistica Hafniensia 35, 160-185.

Coupland, Justine (Ed.), 2000. Small Talk. Pearson Education, Harlow.

Cushing, Steven, 1994. Fatal Words, Communication Clashes and Aircraft Crashes. The University of Chicago Press, Chicago.

Drew, Paul, Heritage, Paul, 1992. Analyzing talk at work: an introduction. In: Drew, P., Heritage, J. (Eds.), Talk at Work: Interaction in Institutional Settings. Cambridge University Press, Cambridge, pp. 3-65.

Falzon, Paul, 2006. Series-initial episodes of pilot-controller VHF radio-mediated spoken communication in air traffic control domain: consequences for turn design and sequential organisation. Paper read at ICCA06, Helsinki, May 2006.

Garfinkel, Harold, 1967. Studies in Ethnomethodology (Prentice-Hall). New edition 1985 (1992) Polity Press, Cambridge.

Halliday, Mark, 1994. PICOP Conversation Culture. Scientifics. British Rail Research.

Heath, Christian, Luff, Paul, 1992. Collaboration and control: crisis management and multimedia technology in London underground line control rooms. Computer Supported Cooperative Work (CSCW) 1, 69-94.

Hopper, Robert, 1992. Telephone Conversation. Indiana University Press, Bloomington.

Houtkoop-Steenstra, Hanneke, 2000. Interaction and the Standardized Survey Interview. Cambridge University Press, Cambridge.

Irvine, Judith T., 1979. Formality and informality in communicative events. American Anthropologist, New Series 81, 773-790.

Järnvägsinspektionen, 1994. Temainspektion samtalsdisciplin. Rapport 1994:01.

Järnvägsinspektionen, 1997. Temainspektion samtalsdisciplin. T1997:8.

Järnvägsinspektionen, 2001. Urspårning och kollision i Strömsbro, 30 mars 2001, U 2001:1.

Järnvägsinspektionen, 2002. Kollision mellan två växlingsrörelser i Göteborg Kville 2002-02-28, U 2001:1.

Järnvägsinspektionen, 2003. Inspektion Samtalsdisciplin. T2003:3.

Katastrofkommissionen, 1987. Tågolyckan i Lerum den 16 november 1987: del I och II. Utredningsrapport Nr 4: 1987.

Linell, Per, in press. Communicative activity types as organisations in discourses and discourses in organisations. In: Tanskanen, S.-K., Helasvuo, M.-L., Johansson, M., Karhukorpi, J., Raitaniemi, M. (Eds.), Discourses in Interaction. John Benjamins, Amsterdam.

Linell, Per, Alemyr, Lotta, Jönsson, Linda, 1993. Admission of guilt as a communicative project in judicial settings. Journal of Pragmatics 19, 153176.

Marlaire, Courtney, Maynard, Douglas, 1990. Standardized testing as an interactional phenomenon. Sociology of Education 63, 83-101.

Maynard, Douglas, Schaeffer, Nora C., 2006. Standardization-in-interaction: the survey interview. In: Drew, P., Raymond, G., Weinberg, D. (Eds.), Talk and Interaction in Social Research Methods. Sage, London, pp. 9-27.

Maynard, Douglas, Houtkoop-Steenstra, Hanneke, Schaefer, N.C., van der Zouwen, Johannes (Eds.), 2002. Standardization and Tacit Knowledge. Interaction and Practice in the Survey Interview. John Wiley, Cambridge.

McCarthy, Michael, 2000. Mutually captive audiences: small talk and the genre of close-contact service encounters. In: Coupland, J. (Ed.), Small Talk. Longman, London, pp. 84-109. 
McHoul, Alexander, 1978. The organization of turns at formal talk in the classroom. Language in Society 7, $183-213$.

Morrow, Daniel, Rodvold, Michelle, Lee, Alfred, 1994. Nonroutine transactions in controller-pilot communication. Discourse Processes 17, 235258.

Murphy, Philippa, 2001. The role of communications in accidents and incidents during rail possessions. In: Harris, D. (Ed.), Engineering Psychology and Cognitive Ergonomics Volume Five. Aerospace and Transportation Systems. Aldershot, Ashgate, pp. 447-454.

Olsson, Eva, Sandblad, Bengt, Kecklund, Lena, 2000. Säkerhetssamtal inom tågtrafik. Nuläge och förändringsbehov. Technical report $2000-033$. Department of Information Technology, Uppsala University.

Pomerantz, Anita, Fehr, B.J., 1997. Conversation analysis: an approach to the study of social action as sense making practices. In: Van Dijk, T.A. (Ed.), Discourse as Social Interaction. Sage Publications, London, pp. 64-91.

Sanne, Johan M., 1999. Creating Safety in Air Traffic Control. (Linköping Studies in Arts and Science, 193) Arkiv Förlag, Lund.

Sanne, Johan M., 2001. Fart och spänning - banarbetare, lokförare och tågtrafikledare om risk och riskhantering. Tema T Rapport 27, 2001, Linköping.

Sanne, Johan M., 2003. Creating trust and achieving safety in air traffic control. In: Summerton, J., Berner, B. (Eds.), Constructing Risk and Safety in Technological Practice. Routledge, London, pp. 140-156.

Schegloff, Emanuel A., 1968. Sequencing in conversational openings. American Anthropologist 70, 1075-1095.

Schegloff, Emanuel A., 1986. The routine as achievement. Human Studies 9, 111-152.

Schegloff, Emanuel A., 1992. Repair after next turn: the last structurally provided defense of intersubjectivity in conversation. American Journal of Sociology 97, 1295-1345.

Stax, Hanne-Pernille, 2004. Paths to precision: probing turn format and turn-taking problems in standardized interviews. Discourse Studies 6, 77-94.

Tykesson-Bergman, Ingela, 2006. Samtal i butik: Språklig interaktion mellan biträden och kunder. ("Conversation in service encounters: Verbal interaction between shop assistants and customers") (Stockholm Studies in Scandinavian Philology, 41.) Department of Nordic Languages, Stockholm.

Wenger, Etienne, 1998. Communities of Practice: Learning, Meaning and Identity. Cambridge University Press, Cambridge.

Westerholm, Adam, Åström, Mattias, 2003. Kognitiv förståelse i dynamiska miljöer - en jämförande studie av radio och telefonmedierad kommunikation inom tågtrafikledning och flygledning. (Master's thesis.) Department of Language and Culture, Linköping.

Zimmerman, Don H., 1992. The interactional organization of calls for emergency assistance. In: Drew, P., Heritage, J. (Eds.), Talk at Work. Cambridge University Press, Cambridge, pp. 418-469. 